\title{
Avaliação da sustentabilidade do município de Vitória do Jari, Amapá, Brasil
}

\author{
Sustainability Assessment of the Municipality of \\ Vitória do Jari, Amapá, Brazil
}

José Ernaldo de Alcantara Junior ${ }^{1}$ José Francisco de Carvalho Ferreira²

\begin{abstract}
1 Graduando na Licenciatura de Geografia, Universidade Federal do Amapá. Bolsista de Iniciação Científica. E-mail: alcantara.ernaldo@gmail.com. 2 Doutor em Geografia e Planeamento Territorial. Pós-Doutor em Desenvolvimento Regional. Docente na graduação de Geografia e nos Programas de Pós-Graduação em Desenvolvimento Regional e em Geografia. Líder do Grupo de Pesquisa "Avaliação da sustentabilidade dos estados e municípios da Amazônia”. E-mail: zfcofer@gmail.com.
\end{abstract}

RESUMO: A avaliação da sustentabilidade de municípios, por meio de indicadores, é bem documentada na bibliografia internacional, embora seja parca nos estados e municípios da Amazônia. Usar os indicadores para avaliar o estágio de desenvolvimento surge da necessidade de uma abordagem que incorpore diversos aspectos além dos econômicos. Assim, este artigo apresenta a avaliação da sustentabilidade do Município de Vitória do Jari, Amapá/Brasil, fazendo uso do método do mínimo e máximo. Os resultados assinalam as debilidades do município, sendo que a sua baixa pontuação na dimensão político/institucional aponta para a necessidade de rever o processo de desenvolvimento municipal.

Palavras-Chave: Avaliação da Sustentabilidade. Indicadores de sustentabilidade. Vitória do Jari. Amapá.

ABSTRACT: Sustainability assessment of municipalities by indicators is well documented in the international bibliography, although it is scares in the states and municipalities of the Amazon. Using indicators to assess the stage of development arises from the need for an approach that incorporates many aspects besides the economic ones. Thus, this article presents the sustainability assessment of the municipality of Vitória do Jari, Amapá/Brazil, using the minimum and maximum method. The results point out the weaknesses of the municipality, and its low score in the political / institutional dimension points to the need to review the municipal development process

Keywords: Sustainability assessment. Sustainability indicators. Vitória do Jari. Amapá.

Sumário: Introdução - 1 Definindo o Desenvolvimento Sustentável- 2 Materiais e Métodos - 2.1 Caracterização do Município de Vitória do Jari;2.1.1 índice de Desenvolvimento Humano (IDH); 2.1.2 Índice de Progresso Social da Amazônia (IPS);2.1.3 Índice de Sustentabilidade dos Municípios da Amazônia (ISMA) - 2.2 Metodologia - 3 Resultados e Discussão - Considerações Finais - Referências

\section{INTRODUÇÃO}

Pensar em alternativas ao atual estado de coisas parece algo vital, uma questão de sobrevivência. $\mathrm{O}$ estado crítico em que se encontra o planeta, atestado por numerosos cientistas de áreas diferenciadas, em relatórios e pesquisas diversos, requer uma reflexão acerca da nossa conduta, enquanto cidadãos, empresários, investidores, especuladores do mercado financeiro, enquanto membros de uma comunidade, de uma sociedade global. Ninguém tem como ficar fora desta urgente reflexão e consequente mudança.

É aqui que entra o conceito de Desenvolvimento Sustentável (DS). Aclamado por uns como um 
modelo alternativo de desenvolvimento, refutado por outros que conclamam se tratar de um enverdecimento do modelo econômico, o conceito, ainda recente, tem tido um sucesso generalizado, desde o início dos anos 1970, quando começaram a ser equacionados, com maior incidência, os problemas ambientais e sociais decorrentes do modelo de desenvolvimento, predominantemente, economicista.

No entanto, apesar de muito sucesso, permeando políticas, programas, planos, projetos, negócios, em diferentes escalas, do local ao global, as críticas têm sido contundentes, profundas e exigem uma séria reflexão, já que a responsabilidade da transformação necessária é de todos e de cada um.

Com este artigo pretende-se apresentar a avaliação da sustentabilidade de um município do estado do Amapá, utilizando indicadores selecionados a partir de fontes públicas, abertas e acessíveis. Estes indicadores são tratados utilizando o método do mínimo e do máximo, permitindo combiná-los em 4 dimensões (econômica, sociocultural, ambiental e político-institucional). Como o objetivo primeiro é avaliar a sustentabilidade do município, pretende-se subsidiariamente aprestar uma reflexão sobre o desempenho dos indicadores e suas variáveis e, com isso, quem sabe, encetar uma reflexão acerca do mundo que queremos e do que precisamos mudar, começando pelo local onde cada um habita.

Num primeiro momento, ter-se-á em conta algumas das características do conceito, procurando uma definição que concentre os aspectos mais relevantes, que auxiliem na seleção de indicadores e suas variáveis. Num segundo momento, nos materiais e métodos, apresenta-se o município e os materiais e a metodologia utilizada para esta avaliação da sustentabilidade. Em seguida, são apresentados os resultados e a discussão, para terminar com as considerações finais.

\section{DEFININDO O DESENVOLVIMENTO SUSTENTÁVEL}

Até ao momento, não existe uma definição comumente aceita de DS. Contudo, a mais conhecida e disseminada de todas é a do Relatório Brundtland, onde se define como aquele "[...] que satisfaz as necessidades do presente sem comprometer a capacidade de as gerações futuras satisfazerem suas próprias necessidades." (CMMAD, 1991, p. 18). Ainda assim, apesar de utilizada pelas instituições e citada com frequência, o fato é que não existe uma definição que convença e faça as pessoas render-se ao conceito, sobretudo se entendido como um modelo alternativo de desenvolvimento, exatamente por ser vago, impreciso e complexo (FERREIRA, 2012, 2013; MAWHINNEY, 2005).

Tendo como ponto de partida a sociedade sustentável, considerada a partir da definição do Relatório Brundtland, Kerk e Manuel (2008) determinaram que esta é aquela em que cada ser humano pode desenvolver-se de uma maneira saudável, obtém educação adequada, vive em um ambiente limpo, numa sociedade equilibrada e segura, usa os recursos não renováveis de modo responsável, por forma a que as gerações futuras não fiquem de mãos vazias, e contribui para um mundo sustentável.

Martins (2004), ao refletir sobre o DS, sugere que sejam feitos alguns questionamentos. As ações em prol do DS satisfazem as necessidades básicas humanas? Promovem a equidade e a justiça social? Comprometem-se com as gerações futuras? Respeitam a autodeterminação dos povos? Respeitam a diversidade cultural e a manutenção do patrimônio ambiental? Promovem a cidadania? Preconizam novos padrões de consumo em harmonia com a natureza?

Wheeler (2004) entende o DS como aquele que melhora, a longo-prazo, a saúde dos sistemas humano e ecológico. O "Guião de Educação para a Sustentabilidade” (Gil et al., 2006, p. 18) identifica a essência do DS como "o suficiente para todos e para sempre”. E Siena (2002) considera que há três caracte- 
rísticas que a maioria das definições tem em comum: uma condição humana desejável, uma condição do ecossistema desejável e equidade duradoura, entre a presente e as gerações futuras e dentro da presente geração.

Ferreira (2012), refletindo sobre o conceito, define-o como o processo de transformações que ocorre, de forma harmoniosa, em várias dimensões e almeja a promoção humana integral, a cidadania plena e a equidade social, a paz e a segurança, um ambiente saudável e ecologicamente equilibrado, no contexto das gerações presentes e futuras e na direção de um mundo sustentável (ver SILVA, 2006).Em outra perspectiva, Miller e Spoolman (2012, p. 5) definem a sustentabilidade como

[...] a capacidade dos sistemas naturais da Terra e dos sistemas culturais humanos de sobreviver, prosperar e se adaptar às mudanças nas condições ambientais no longo prazo, conceito que também se refere a pessoas preocupadas em transmitir um mundo melhor para as gerações vindouras.

Pode observar-se, assim, que definir DS não é, de todo, tarefa fácil, já que se trata de um conceito complexo, o que, em certo sentido, explica a variedade dos indicadores selecionados, dentro de quatro dimensões: político-institucional, econômica, ambiental e sociocultural.

\section{MATERIAIS E MÉTODOS}

\subsection{CARACTERIZAÇÃO DO MUNICÍPIO DE VITÓRIA DO JARI}

O município de Vitória do Jari foi desmembrado do Município de Laranjal do Jari e teve sua criação constituída a partir da Lei no 0171, de 08 de setembro de 1994, sendo, desta forma, o município mais novo do Estado do Amapá. Localiza-se na mesorregião sul, mais precisamente no extremo Sul do Estado, com uma área total de $2.508 .979 \mathrm{~km}^{2}$. Sua população em 2010 era de 12.428 habitantes (IBGE, 2010), com estimativa de 15.605, em 2018, sendo o oitavo município em população do Estado. Vitória do Jari (figura 1) tem como limites os Municípios de Laranjal do Jari e de Mazagão além dos municípios Paraenses de Almeirim e Gurupá.

O município surgiu a partir da perspectiva da população em ver transformados os impostos pagos pela CADAM (empresa que explora minério na região) em benefícios para a região (MEDEIROS; SENA, 2018). A empresa CADAM fica localizada no Distrito de Monte Dourado, que pertence ao Estado do Pará, às margens do Rio Jari, já o município de Vitória do Jari se desenvolveu também às margens do Rio Jari, por sua vez, no lado Amapaense e em decorrência das atividades do outro lado do Jari. 
Figura 1- Mapa de Localização do município de Vitória do Jari

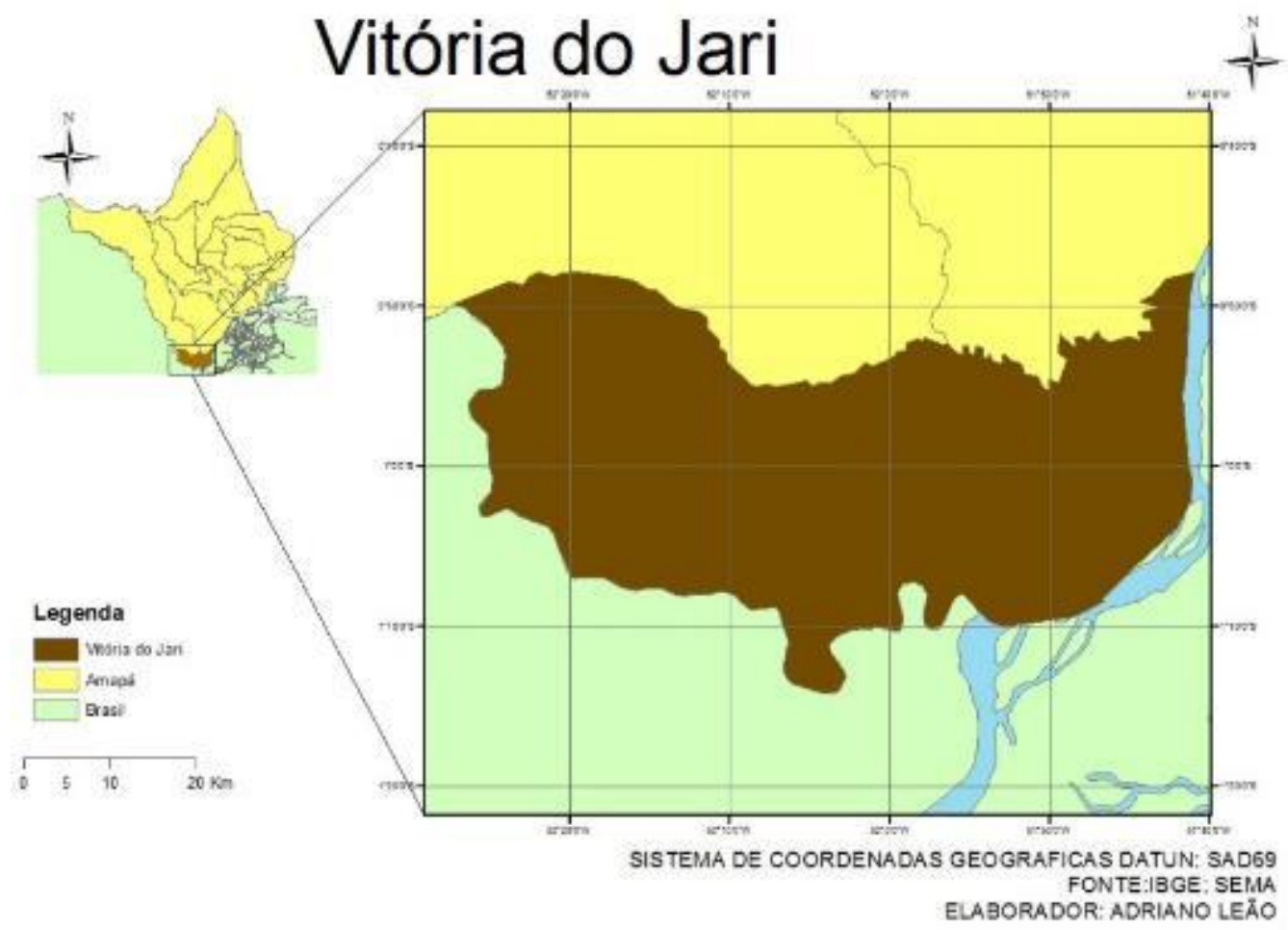

Segundo o Governo do Estado do Amapá, a economia tem como base a agricultura, além de comércio e serviços. Como destaque da agricultura tem-se as plantações de milho, banana, melancia e abobora. Destaca-se também a criação de gado bovino e bubalino, na pecuária.

As empresas Jari Celulose e a CADAM, sediadas no Estado do Pará, têm grande influência na economia de Vitória do Jari, gerando centenas de empregos para os habitantes do município (LIMA, 2016). Destaca-se ainda a extração de caulim, além da extração de Castanha-do-Pará, esta última realizada por meio de uma cooperativa. A maior parte da renda da cidade é destinada aos servidores públicos, além destes, no setor terciário, destaca-se pequenos comércios, bares, boates e lanchonetes.

\subsection{1 Índice de Desenvolvimento Humano (IDH)}

O Índice de Desenvolvimento Humano (IDHM) do município de Vitória do Jari foi 0,619, em 2010, o que o classifica no Desenvolvimento Humano Médio (faixa de desenvolvimento humano que varia entre 0,600 e 0,699). O Índice de Desenvolvimento Humano Municipal (IDHM) é uma medida composta por três dimensões para a avaliação do desenvolvimento humano: longevidade, educação e renda. O índice tem variação entre 0 e 1, quanto mais próximo de 1, maior é o desenvolvimento humano (tabela 1).

Tabela 1- IDH por UF: Brasil, Amapá e Vitória do Jari (2000-2010)

\begin{tabular}{l|c|c|c|c|c|c|c|c|c|c|c|c}
\hline \multirow{2}{*}{ UF } & \multicolumn{3}{|c|}{ IDHM } & \multicolumn{2}{c|}{ IDH LONGEVIDADE } & \multicolumn{3}{c|}{ IDH EDUCAÇÃO } & \multicolumn{3}{c}{ IDH RENDA } \\
\cline { 2 - 39 } & 2000 & 2010 & $\Delta \%$ & 2000 & 2010 & $\Delta \%$ & 2000 & 2010 & $\Delta \%$ & 2000 & 2010 & $\Delta \%$ \\
\hline BRASIL & 0,612 & 0,727 & 18,79 & 0,727 & 0,816 & 12,24 & 0,456 & 0,637 & 39,69 & 0,692 & 0,739 & 6,79 \\
\hline AMAPÁ & 0,577 & 0,708 & 22,70 & 0,711 & 0,813 & 14,35 & 0,424 & 0,629 & 48,35 & 0,638 & 0,694 & 8,78 \\
\hline VITÓRIA DO JARI & 0,459 & 0,619 & 34,85 & 0,670 & 0,781 & 16,56 & 0,271 & 0,517 & 90,77 & 0,534 \\
\hline
\end{tabular}

Fonte: PNUD (2013) 
Com a análise da Tabela 01, é possível perceber que todos os indicadores tiveram melhora, quando comparados os anos de 2000 e 2010. Ao todo, a taxa de variação se comportou de maneira positiva, com um aumento total de 34,85\% em relação ao ano de 2000 .

A dimensão da educação foi a que mais se destacou com um aumento de 90,77\%, majorando consideravelmente a proporção de crianças e jovens que frequentam ou que completaram determinados ciclos. Vale destacar, também, que a variação percentual dos índices do município de Vitoria do Jari foi maior do que a do Estado do Amapá e do Brasil.

\subsection{2 Índice de Progresso Social da Amazônia (IPS)}

Na tabela 2, encontram-se dados do Índice de Progresso Social da Amazônia (IPS), índice que a analisa o progresso social usando três dimensões: as Necessidades Humanas Básicas, os Fundamentos do Bem-Estar e as Oportunidades. Originalmente, o IPS Amazônia foi publicado em 2014, sendo a primeira no mundo a realizar de maneira subnacional utilizando a escala de Estados e Munícipios, utilizando um método original para adaptação do IPS da escala Global para uma escala Subnacional. Na Amazônia Brasileira, foi avaliado o IPS de cada um de seus 772 municípios.

Tabela 2- Índice de Progresso Social da Amazônia (Brasil, Amazônia, Amapá e Vitória do Jari)

\begin{tabular}{|c|c|c|c|c|}
\hline DIMENSÕES E COMPONENTES & BRASIL & AMAZÔNIA & AMAPÁ & VITÓRIA DO JARI \\
\hline Dimensão 1 - Necessidades humanas básicas & 71,6 & 58,75 & 61,9 & 63,95 \\
\hline Nutrição e cuidados médicos básicos & 80,01 & 72,46 & - & 77,50 \\
\hline Água e Saneamento & 74,87 & 35,35 & - & 37,80 \\
\hline Moradia & 92,03 & 72,48 & - & 92,10 \\
\hline Segurança pessoal & 39,49 & 54,72 & - & 48,30 \\
\hline Dimensão 2 - Fundamentos para o Bem-estar & 70,42 & 64,84 & 60,9 & 58,51 \\
\hline Acesso ao conhecimento básico & 67,13 & 60,61 & - & 60,40 \\
\hline Acesso à informação e comunicação & 63,44 & 53,36 & - & 14,08 \\
\hline Saúde e bem-estar & 68,35 & 70,57 & - & 72,78 \\
\hline Sustentabilidade dos ecossistemas & 82,76 & 74,85 & - & 86,04 \\
\hline Dimensão 3 - Oportunidades & 61,18 & 48,33 & 47,6 & 45,53 \\
\hline Direitos individuais & 65,39 & 45,22 & - & 36,75 \\
\hline Liberdade individual e de escolha & 81,99 & 64,41 & - & 58,54 \\
\hline Tolerância e inclusão & 63,59 & 64,58 & - & 70,11 \\
\hline Acesso à educação superior & 33,76 & 19,1 & - & 16,73 \\
\hline VALOR MÉDIO & 67,73 & 57,31 & 56,8 & 56,00 \\
\hline
\end{tabular}

Fonte: SANTOS et al. (2014).

A avaliação do Município de Vitória do Jari teve como média o valor de 56,00, colocando-o na posição 450 no ranking dos municípios do Amazônia Brasileira. Comparando os valores do IPS, expresso na tabela 2, constata-se que Vitória do Jari está abaixo da média do Brasil, da Amazônia e do Estado.

Observando a tabela 2, verifica-se onde o Município de Vitória do Jari se destacou de maneira negativa no Acesso à informação e comunicação $(14,08)$, Acesso à educação superior $(16,73)$, Direitos individuais $(36,75)$ e Água e saneamento $(37,80)$, sendo que dois desses indicadores estão na dimensão Oportunidades. 
Se destacando positivamente estão os indicadores: Moradia (92,10), Sustentabilidade dos ecossistemas $(86,04)$, Nutrição e cuidados médicos básicos $(77,50)$ e saúde e bem-estar $(72,78)$, destacando-se mais uma vez a dimensão das Oportunidades, sem nenhum dos indicador entre os primeiros 4 da tabela.

\subsection{3 Índice de Sustentabilidade dos Municípios da Amazônia (ISMA)}

Analisando o índice de sustentabilidade dos municípios da Amazônia, verifica-se que Vitória do Jari apresentava um índice de 0,550 no ano de 2000, sendo o melhor colocado no ranking Amapaense, valor esse que colocava o município na faixa média que vai de 0,478 até 0,650 . No ano de 2010 o município teve um índice de apenas 0,390, colocando-o na décima primeira posição entre os 16 municípios.

A dimensão que mais chama atenção é a político Institucional, que, no ano de 2000, possuía um índice de 0,196, e no ano de 2010 o índice era de apenas 0,063, contribuindo significativamente para a queda do índice geral do município. Em nenhuma dimensão do município pôde-se observar aumento nos índices, o que mais se aproximou foi a dimensão ambiental que, em 2000, tinha um valor de 0,126 e, em 2010, teve o mesmo valor (tabela 3).

Tabela 3 - Resultado do Índice de sustentabilidade Municipal dos municípios da Amazônia

\begin{tabular}{|c|c|c|c|}
\hline \multirow{2}{*}{\multicolumn{2}{|c|}{ ISMA - Amapá }} & \multicolumn{2}{|c|}{ ANOS } \\
\hline & & 2000 & 2010 \\
\hline \multirow{4}{*}{ 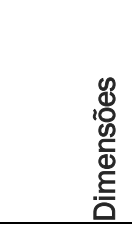 } & Político Institucional & 0,196 & 0,063 \\
\hline & Econômico & 0,129 & 0,105 \\
\hline & Ambiental & 0,126 & 0,126 \\
\hline & Sociocultural & 0,099 & 0,096 \\
\hline \multicolumn{2}{|l|}{ TOTAL } & 0,55 & 0,39 \\
\hline
\end{tabular}

Fonte: SILVA; AMIN; NUNES (2015).

\subsection{METODOLOGIA}

Os materiais utilizados para este artigo incidem, sobretudo, em dados estatísticos de fontes oficiais diversas como o IBGE, DATASUS, INPE, FINBRA, ATLAS BRASIL, ANATEL, ÍNDICE DE PROGRESSO SOCIAL, MINISTÉRIO DA SAÚDE, PROGRAMA CIDADES SUSTENTÁVEIS, assim como materiais bibliográficos, tanto referências nacionais quanto internacionais.

Metodologicamente, este artigo tem como base trabalhos de Ferreira (2012, 2013), Tostes e Ferreira (2017), Siena (2002) e considera, entre outras, a metodologia do Índice de Sustentabilidade dos Municípios da Amazônia - ISMA (SILVA; AMIN; NUNES, 2015), o "Modelo de Indicadores para mensuração do desenvolvimento sustentável da Amazônia” de Ribeiro (2002), Kerk e Manuel (2008), as apontadas por Silva, Souza e Leal (2012), Bellen (2004), Braga et al. (2004), Santos et al. (2014) e Vale, Toledo e Vieira (2018), tendo como ponto de partida uma visão mais abrangente e sistêmica, que suplante a prevalência da dimensão econômica.

$\mathrm{Na}$ avaliação da sustentabilidade, algumas questões metodológicas são equacionadas com a finalidade de se chegar a um valor que incorpore os aspectos mais relevantes, no intuito de perscrutar o progresso de um dado território em direção ao desenvolvimento sustentável, questões para as quais se atentará, em seguida. 
Uma dessas questões é a padronização dos indicadores e suas variáveis, dado que têm natureza diversa e métricas próprias (SIENA, 2002). Assim, é necessário um procedimento que possibilite utilizá-los na mesma unidade de medida. Esse procedimento é feito com o método do mínimo e do máximo, considerando a relação positiva e negativa que os indicadores e as variáveis possam ter com a sustentabilidade.

Com a utilização desse método, é possível padronizar indicadores de diferentes escalas em uma única escala que varia, neste caso, entre 0 e 100, ou seja, quanto mais próximo de 100, maior a contribuição daquele indicador para a sustentabilidade, e quanto mais próximo de 0 , menor a sua contribuição para a sustentabilidade. Neste contexto, é fundamental analisar, previamente, a relação do indicador com a sustentabilidade, ou seja, se é uma relação positiva ou negativa. A partir dessa análise, opta-se por uma das fórmulas a seguir para a normalização.

Fórmulas - Padronização dos indicadores

$X_{N}^{+}=\frac{X^{+}-X_{\min }^{+}}{X_{\max }^{+}-X_{\min }^{+}} \times 100(1)$

$X_{N}^{-}=1-\frac{X^{-}-X_{\min }^{-}}{X_{\max }^{-}-X_{\min }^{-}} \times 100(2)$

Nas fórmulas de cálculo apresentadas, $X_{N}^{+}$(1) corresponde ao indicador normalizado, cuja relação com a sustentabilidade é positiva, e $X_{N}^{-}$(2) ao indicador normalizado, cuja relação com a sustentabilidade é negativa; $X_{\min }^{+}$e $X_{\max }^{-}$correspondem, respectivamente, ao menor e maior valor daquele indicador, segundo a referência adotada; e $X^{+}$e $X^{-}$correspondem aos valores dos indicadores a ser normatizados, de acordo com a sua relação com a sustentabilidade (positiva ou negativa) (BÖHRINGER; JOCHEM, 2007).

Outra questão relevante prende-se com a abrangência da avaliação, isto é, o alcance dos valores de referência. Esta pode ser local, nacional ou mesmo internacional. Neste encalce, entende-se que a utilização de valores médios nacionais, de valores mínimo e máximo dos indicadores à escala nacional e de padrões locais, nacionais e internacionais, segundo sua existência e disponibilidade, poderá assinalar resultados mais perspicazes, permitindo observar o desempenho de Vitória do Jari em um contexto mais alargado, que não somente o do Estado do Amapá ou o dos Estados da Amazônia.

Neste contexto, foi tido em conta o documento "Metas de Sustentabilidade para os Municípios Brasileiros” (PROGRAMA CIDADES SUSTENTÁVEIS, 2012), importante referência nacional, tanto no que concerne aos indicadores, quando às metas e padrões. Foi igualmente ponto de referência o Índice de Progresso Social da Amazônia (SANTOS et al., 2014).

Relativamente à importância dos indicadores, esta avaliação assume que os indicadores têm pesos iguais na composição final da pontuação. Contudo, em algumas metodologias, os autores atribuem pesos, de acordo com a compreensão que têm da importância de cada indicador, procedimento que é comum em vários índices (SIENA, 2002; SILVA; AMIN; NUNES, 2015). Assume-se que, neste artigo, todos os indicadores têm pesos iguais, já que se entende que tudo está interrelacionado e interdependente, dentro do âmbito de uma visão sistêmica, que deve iluminar um planejamento que se quer, igualmente, sistêmico (BARCELLOS; BARCELLOS, 2004).

O procedimento é simples e pretende ser de uso prático. O valor final obtido para cada dimensão resulta da média das subdimensões, sendo estas resultado da média simples dos indicadores que a constituem e estes o resultado da média simples das variáveis pelas quais são compostos. O resultado final será apresentado por dimensão e indicador. 


\section{RESULTADOS E DISCUSSÃO}

Para obtenção dos resultados dessa pesquisa, foram utilizadas 51 variáveis, 27 indicadores dispostos em 4 dimensões. Os resultados da avaliação podem ser encontrados na tabela 4 e no gráfico 1. Na tabela 4 encontra-se, de maneira detalhada, os indicadores de cada dimensão e seus respectivos valores, assim como os valores médios de cada dimensão.

Tabela 4- Indicadores de Sustentabilidade do município de Amapá

\begin{tabular}{|c|c|c|c|}
\hline Dimensão & Indicador & Valor do Indicador & $\begin{array}{c}\text { Valor médio por } \\
\text { Dimensão }\end{array}$ \\
\hline \multirow{3}{*}{ Econômica } & Nível de Renda & 40,56 & \multirow{3}{*}{46,82} \\
\hline & Desemprego & 54,78 & \\
\hline & Vulnerabilidade & 44,95 & \\
\hline \multirow{6}{*}{ Sociocultural } & Longevidade & 57,03 & \multirow{6}{*}{54,94} \\
\hline & Gravidez na infância e adolescência & 92,01 & \\
\hline & Saúde e bem-estar & 63,80 & \\
\hline & Escolaridade & 46,80 & \\
\hline & Qualidade do Ensino & 51,15 & \\
\hline & Qualidade Habitacional & 41,42 & \\
\hline \multirow{6}{*}{ Ambiental } & Saneamento básico & 55,33 & \multirow{6}{*}{58,22} \\
\hline & Preservação Ambiental & 65,25 & \\
\hline & Gestão Ambiental & 21,43 & \\
\hline & Resíduos sólidos urbanos & 50,00 & \\
\hline & Biodiversidade/proteção dos ecossistemas & 60,82 & \\
\hline & Qualidade do Ar & 96,50 & \\
\hline \multirow{4}{*}{ Político/Institucional } & Governança & 17,65 & \multirow{4}{*}{23,34} \\
\hline & Capital Social & 16,00 & \\
\hline & Qualidade do quadro funcional & 45,08 & \\
\hline & Capacidade de arrecadação & 4,47 & \\
\hline
\end{tabular}

Fonte: Elaborado pelos autores, 2019.

O Valor médio obtido pelo muncípio Vitória do Jari na Avaliação da sustentabilidade foi de apenas 45,83 pontos, valor considerado baixo, sendo um dos piores do Estado do Amapá, ficando abaixo do valor médio (50 pontos), como se expressa na tabela 4, colocando o município em uma situação intermediária (entre os 40 e os 60 pontos), com seu resultado mais próximo da base desta classe.

Destaca-se de maneira positiva a dimensão ambiental com um valor médio de 58,22 e a dimensão sociocultural com um valor médio de 54,94. Já a dimensão com o valor mais baixo foi a Político/Instituicional, com um valor médio de apenas 23,34, contribuindo para o baixo valor total do município, como se pode constatar no gráfico 1. 
Gráfico 1- Dimensões dos indicadores do município de Vitória do Jari

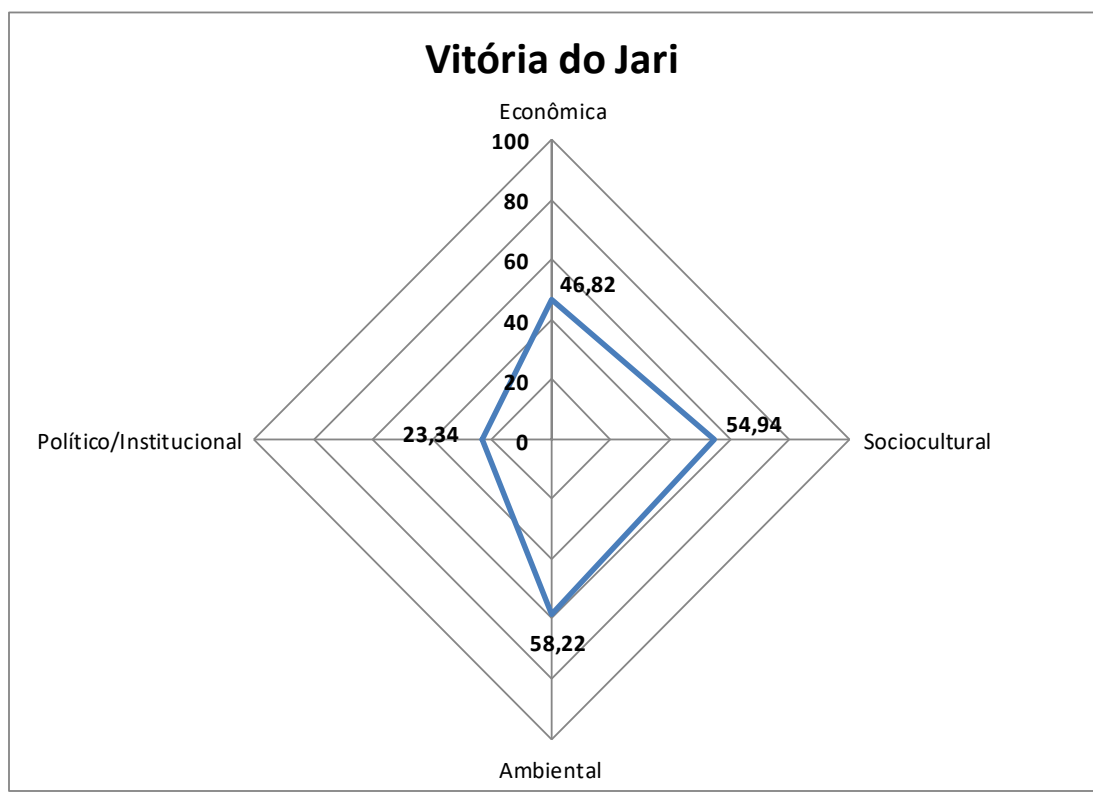

Fonte: Elaborado pelos autores, 2019.

A dimensão Político/Institucional é a que apresenta o valor mais baixo de todas as dimensões analisadas, onde os indicadores "Capacidade de arrecadação" (4,47), "capacidade de investimento" $(7,30)$, "Capital Social” (16,00) e "Governança" $(17,65)$ contribuíram de forma negativa para o desempenho desta dimensão. Os indicadores que se destacam positivamente são o de "Qualidade do quadro funcional”, com uma pontuação de 45,08 e "Saúde Financeira" com 49,56 pontos, contribuindo para que essa dimensão não tivesse uma média ainda menor.

A dimensão ambiental apresenta o maior valor das dimensões analisadas (58,22). O indicador que mais pontou foi "Qualidade do ar" com um valor de 96,50, contribuindo para o aumento da média dessa dimensão. Outros indicadores que se destacaram foram "Preservação Ambiental" e "Biodiversidade/proteção dos ecossistemas" com os respectivos valores e 65,25 e 60,82. O menor valor dessa dimensão foi o indicador "Gestão Ambiental", com o valor de 21,43.

$\mathrm{Na}$ dimensão Sociocultural o indicador "cultura", que avalia os investimentos municipais em cultura, teve um valor de 0,00, outro indicador que teve um valor baixo foi o de "assistência à saúde", com um valor 13,75. Em contrapartida, o indicador "Trânsito" (100), "Gravidez na infância e na adolescência" $(92,01)$ e "Informação e comunicação" (80,29), contribuíram para o aumento da média dessa dimensão.

$\mathrm{Na}$ dimensão econômica, os 4 indicadores apresentaram valores aproximados, entretanto, relativamente baixos. O único indicador que foi além da média foi o do "desemprego", com um valor de 54,78, talvez em função dos empregos gerados pelas empresas nos municípios vizinhos. Essa dimensão teve uma pontuação de 46,82, considerada abaixo do valor médio na escala 0-100.

\section{CONSIDERAÇÕES FINAIS}

O compromisso por uma sociedade sustentável, que seja capaz de pensar sincrônica e diacronicamente, isto é, capaz de distribuir as vantagens do processo de desenvolvimento por todas as sociedades e em tempos diferentes, considerando as gerações atuais e futuras, é um desafio ímpar. São muitos os indí- 
cios de que nossa conduta está a interferir com o Planeta do qual somos parte integrante. A utilização dos indicadores mostra que a mudança urge. Esta é uma responsabilidade de todos e de cada um, do cidadão cônscio ao empresário e investidor responsável, ao Estado fomentador do Bem-comum.

A sustentabilidade surge para muitos como um mundo de possibilidades de recriar seus negócios, de permanecer com lucros crescentes, de continuar explorando, avidamente, os recursos de um planeta que é vivo e finito. No entanto, muitas têm sido as tentativas e experiências levadas a cabo, um pouco por todo o mundo, no sentido de diminuir nosso poder destruidor e de tentar restabelecer a relação de harmonia com a natureza. Mas não nos iludamos, há ainda muito a fazer.

Apesar das dificuldades em ser por todos aceito, dado o fato de ser vago, complexo, engenhoso e incompleto, e justificar, muitas vezes opções e atitudes insustentáveis, o conceito de DS mostra-se válido para aqueles que buscam criar uma sociedade mais justa, fraterna, equilibrada e em um ambiente saudável e ecologicamente equilibrado, muito embora requeira uma outra atitude e outros valores que não aqueles que são os causadores da situação atual, isto é, precisa-se reinventar nossa civilização.

Um passo importante para essa sociedade sustentável é decidir que sustentabilidade se quer, quando se quer e em que termos se quer. Neste sentido, a utilização de indicadores mostra isso mesmo, a urgente necessidade de se pensar que futuro se quer para uma nova sociedade, que se quer inclusiva, respeitadora do meio ambiente, justa, equilibrada, com saúde, com, no mínimo, os direitos fundamentais verdadeiramente respeitados e assegurados para todos os que estão próximos, como para todos os que estão longe e os que hão de vir.

\section{REFERÊNCIAS}

BARCELLOS, Paulo F. P.; BARCELLOS, Luiz F. P. Planejamento urbano sub perspectiva sistêmica: considerações sobre a função social da propriedade e a preocupação ambiental. Revista da FAE, Curitiba, v. 7, n. 1, p. 129-144, jan/jun 2004.

BELLEN, Hans M. van. Desenvolvimento Sustentável: uma descrição das principais ferramentas de avaliação. Ambiente \& Sociedade, Vol. VII, N. ${ }^{\circ}$ 1, Jan./Jun., 2004, p. 67-87.

BÖHRINGER, C.; JOCHEM, P. E. Measuring the immeasurable - A survey of sustainability indices. Ecological Economists, v. 63, n. 1, p. 1-8, 2007.

BRAGA, Tânia M. et al. Índices de sustentabilidade municipal: o desafio de mensurar. Nova Economia, 14 (3), Setembro-Dezembro, 2004.

COMISSÃO MUNDIAL SOBRE MEIO AMBIENTE E DESEVOLVIMENTO (CMMAD). Nosso Futuro Comum. Rio de Janeiro: Editora da Fundação Getúlio Vargas, 1991.

FERREIRA, José F. C. A Sustentabilidade do Alto Douro Vinhateiro: realidade ou utopia? Contributo para a avaliação e melhoria da sustentabilidade da região. Tese (Doutorado em Geografia e Planeamento Territorial), Faculdade de Ciências Sociais e Humanas (UNL), Lisboa, 2012.

Avaliação da Sustentabilidade: Limites e Possibilidades no Alto Douro Vinhateiro, Portugal. Revista Sustentabilidade em Debate - Brasília, V. 4, n. 2 p. 168-193, jul/dez, 2013.

GIL, Helena (Org.) et al. Educação para a Sustentabilidade. Guião da Sustentabilidade para a Educação - Carta da Terra. Lisboa: Ministério da Educação, 2006.

INSTITUTO BRASILEIRO DE GEOGRAFIA E ESTATÍSTICA (IBGE). Cidades" Amapá» Laranjal" estimativa da população 2018. Disponível em: <http://www.cidades.ibge.gov.br/xtras/temas.php? 
lang $=\& c o d m u n=160020 \& i d t e m a=130 \&$ search=amapa $\mid$ laranjal $\mid$ estimativa-da-populacao-2018>. Acesso em: 03 jul. 2018.

KERK, Guert van; MANUEL, Arthur R. A comprehensive index for a sustainable society: The SSI the Sustainable Society Index. Ecological Economics, 66, 2008, p. 228-242.

LIMA, Janira D. Os desafios da gestão dos resíduos sólidos no amapá: o caso dos municípios de pequeno porte. Repositório Institucional da UFPA. Macapá, 2016.

MARTINS, Sérgio. R. Desenvolvimento Sustentável: desenvolvendo a Sustentabilidade. 2004. Disponivel em: https://repositorio.ufsc.br/bitstream/handle/123456789/128116/DS\%20Sergio\% 20Martins.doc?sequence=4. Acessado em: 20 de nov. 2018 .

MAWHINNEY, Mark. Desenvolvimento Sustentável. Uma Introdução ao debate ecológico. São Paulo: Edições Loyola, 2005.

MILLER, G. Tyler e SPOOLMAN, Scott E. Ecologia e Sustentabilidade. Tradução da $6^{a}$ Edição NorteAmericana. São Paulo: Cengage Learning, 2012

PROGRAMA CIDADES SUSTENTÁVEIS. Metas de Sustentabilidade para os Municípios Brasileiros (Indicadores de Referência), 2012. Disponível em: www.cidadessustentaveis.org.br. Acessado em: 20 de nov. de 2018.

RIBEIRO, Adagenor L. Modelo de indicadores para mensuração do desenvolvimento sustentável na Amazônia. 397 fls. Tese (Doutorado em Ciências: Desenvolvimento Sustentável), Universidade Federal do Pará, NAEA, Belém, 2002.

SANTOS, Daniel et al. Índice de Progresso Social na Amazônia Brasileira. IPS Amazônia 2014. Belém-Pa: Imazon, 2014

SIENA, Osmar. Método para avaliar o progresso em direção ao desenvolvimento sustentável. Tese (Doutorado em Engenharia de Produção), Universidade Federal de Santa Catarina, Florianópolis, 2002.

SILVA, Antônio S. da; SOUZA, José G. de; LEAL, Antônio C. Qualidade de vida e meio ambiente: experiência de consolidação de indicadores de sustentabilidade em espaço urbano. Revista Sustentabilidade em Debate - Brasília, V. 3, n. 2 p. 177-196, jul/dez, 2012.

SILVA, Christian. L. (Org.). Desenvolvimento Sustentável. Um Modelo analítico integrado e adaptativo. Petrópolis: Editora Vozes, 2006.

SILVA, Fábio Carlos da; AMIN, Mario Miguel; NUNES, Silvia Ferreira (Org.). Sustentabilidade dos Municípios da Amazônia. Belém: NAEA, 2015.

TOSTES, José A.; FERREIRA, José F. C. Avaliação da Sustentabilidade na Amazônia: a mesorregião Norte do Amapá. G\&DR, vol. 13, n. 1, p. 198-223, Jan-abr/2017, Taubaré, SP, Brasil.

VALE, Francinelli A. F.; TOLEDO, Peter M.; VIEIRA, Ima C. G. Análise comparativa de indicadores de sustentabilidade entre estados da Amazônia Legal. Sustentabilidade em Debate, Brasília, v. 9, n. 1, p. 2014-231.

WHEELER, Stephen. Planning for Sustainability. Creating livable, equitable, and ecological communities. Oxon: Routledge, 2004. 